\title{
ANKSTYVOS KINEZITERAPIJOS POVEIKIS MOBILUMUI PO KLUBO ENDOPROTEZAVIMO
}

\author{
Vita Lizdeniené $\dot{1}^{1}$ Svetlana Lenickienè ${ }^{2}$ \\ ${ }^{1}$ Vilniaus universiteto Medicinos fakultetas, ${ }^{2}$ Vilniaus universiteto ligoninès Santariškiu klinikos, Vil- \\ niaus universiteto Medicinos fakulteto Reabilitacijos, fizinès ir sporto medicinos centras
}

Raktažodžiai: ankstyva kineziterapija, mobilumas, klubo endoprotezavimas.

\begin{abstract}
Santrauka
Taikant naują ankstyvą kineziterapijos metodiką po klubo endoprotezavimo operacijos pacientai greičiau sveiksta, anksčiau atsistato buvęs darbingumas. Tai leidžia pacientus iš ligoninès išleisti trečią ar ketvirtą parą po operacijos. Mūsų tyrimo tikslas: ankstyvos kineziterapijos metodikos itaka mobilumui po klubo endoprotezavimo operacijos ūmiuoju periodu. Tyrimas atliktas Vilniaus universiteto Santariškių klinikų Ortopedijos - traumatologijos skyriuje nuo $2015 \mathrm{~m}$. balandžio mèn. iki $2016 \mathrm{~m}$. kovo mèn. Tyrime dalyvavo 60 pacientų, kuriems buvo atliktas klubo endoprotezavimas, priekiniu šoniniu operaciniu pjūviu. Tyrime dalyvavo 34 moterys ir 26 vyrai. Vertintas mobilumas pagal 10 metrų èjimo testą, papildomai fiziniam pajègumui ịvertinti matuotas pulsas prieš testo atlikimą, tik atlikus, po $1 \mathrm{~min}$, po $3 \mathrm{~min}$, po $5 \mathrm{~min}$, taip pat vertinta koju atitraukejjų, pritraukejjų, kelio tiesėjų izometrinè raumenų jèga rankiniu Lafayette dinamometru. Tyrimo rezultatai atskleidè, kad ankstyva kineziterapija labiau didina mobilumą, raumenų jègą nei ịprasta kineziterapija. Gauti statistiškai reikšmingi skirtumai $(p<0,05)$ tarp mobilumo, raumenų jëgos pokyčių tiriamojoje ir kontrolinèje grupėse.
\end{abstract}

\section{Ivadas}

Sąnariai mobilumą užtikrinanti žmogaus skeleto dalis. Sutrikus sąnario veiklai žmogus susiduria ne tik su medicininėmis, bet ir su socialinèmis bei psichologinèmis problemomis. Degeneracinès ir uždegiminès sąnarių ligos dažniausia sąnarių skausmų priežastis [1]. Dél skausmo sumažèja judesių amplitudès, darbinę veiklą ir gyvenimo būdą keičia žmogaus sutrikusios sąnario funkcijos [2]. Kai judejjimo ribotumas, skausmas tiek ramybejje, tiek fizinio aktyvumo metu tampa nebepakeliamas, nuskausminamieji vaistai nepadeda, o taikomas gydymas pasidaro neefektyvus, dažniausiai pasirenkamas radikalus gydymo būdas sąnario endoprotezavimo operacija [3].

Endoprotezavimo operaciju mūsų šalyje daugèja kiekvienais metais. Lietuvos statistikos duomenimis, 2013 metais atlikta 3776 klubo artroplastikos ir 1016 klubo revizinès artroplastikos operacijos, t. y. 14 proc. daugiau nei 2012 metais [4]. Laukiančių operacijos šiuo metu yra daugiau nei 20000 .

Atliekant sąnario keitimo operaciją gydymo rezultatai priklauso nuo protezu modernumo, operacijos technikos bei pooperacinès reabilitacijos. Po klubo sąnario endoprotezavimo operacijos, kaip rodo moksliniai tyrimai, tiek pooperaciniu laikotarpiu, tiek padedant pacientui grịžti prie kasdieninès veiklos atstatant funkcines galimybes labai svarbi yra kineziterapija [5]. W. Stryla (2013) su bendraautoriais teigia, kad kineziterapija, pradeta taikyti akstyvuoju pooperaciniu laikotarpiu, padeda sumažinti komplikacijų tikimybę [6].

Pasak R. Berger (2009) anksčiau gydymo stacionare trukmè po klubo sąnario endoprotezavimo operacijos tęsdavosi keletą savaičiu, buvo skiriamas lovos rèžimas [7]. Remiantis atliktų tyrimų duomenų rezultatais, gulèjimo ligoninejje trukmé po klubo endoprotezavimo operacijos trumpinama. Jau nuo 2004 m Danijoje pradèta taikyti ankstyva kineziterapijos programa po klubo endoprotezavimo [8]. H. Husted (2011) su kolegomis teigia, kad taikant naują ankstyvą kineziterapijos metodiką po klubo endoprotezavimo operacijos pacientai greičiau sveiksta, anksčiau atsistato buvęs darbingumas. Tai leidžia pacientus iš ligoninès išleisti trečią ar ketvirtą parą po operacijos. Taigi, ankstyva pooperacinè kineziterapija padeda ne tik grąžinti ligoniui savarankiškumą, bet ir sumažina hospitalizacijos trukmę bei gydymo išlaidas [9].

S. Winther su kt. bendraautoriais (2015) atliko tyrimą Norvegijos universiteto ligoninëje nuo $2010 \mathrm{~m}$. rugsejjo ir 2012 m. gruodžio, kurio metu buvo stebimi pacientai iki 
1 metu laiko po klubo endoprotezavimo operacijos, jiems buvo taikyta ankstyva kineziterapija. Buvo susirūpinta ankstyvos metodikos efektyvumu, ar tai yra saugu ir ar greitas išrašymas iš ligoninès gali padidinti komplikacijų skaičių. Autoriai išvadose teigè, kad pacientai džiaugèsi ligonineje praleidę trumpesnị laiką, padidèjusiu funkcionalumu, pagerèjusia gyvenimo kokybe, sveikata [10].

N. Beyer ir C. Suetta (2013) savo straipsnyje teigia, kad ankstyvos kineziterapijos naudojimas lèmé gerokai sumažéjusių komplikacijų skaičių po klubo endoprotezavimo operacijų. Tačiau vyresnio amžiaus pacientai turi didesnę riziką prarasti raumenų masę ir jègą po operacijos, lyginant su jaunesniais. Todèl vyresnio amžiaus pacientams po operacijos turètų būti taikomas intensyvus mokymas. Daugèja irodymu, kad intensyvus mokymas po operacijos yra veiksmingas atkuriant raumenų funkciją vyresnio amžiaus pacientams po ekstrinių ar planinių operacijų [11].

A. Pogorzała su bendraautoriais (2013) atliko tyrimą, kurio tikslas buvo išanalizuoti prieš ir po klubo sąnario endoprotezavimo operacijos eisenos greiț 86 pacientams, taikant 10 m ejjimo testą. Rezultatai parode, kad po taikyto gydymo statistiškai reikšmingai padidèjo èjimo greitis [12].

Šio darbo tikslas: ankstyvos kineziterapijos metodikos įtaka mobilumui po klubo endoprotezavimo operacijos ūmiuoju periodu.

\section{Tyrimo organizavimas ir metodai}

Tyrimas atliktas Vilniaus universiteto Santariškių klinikų Ortopedijos - traumatologijos skyriuje nuo $2015 \mathrm{~m}$. balandžio mèn. iki $2016 \mathrm{~m}$. kovo mèn. Tyrime dalyvavo 60 pacientų, kuriems buvo atliktas klubo endoprotezavimas, priekiniu - šoniniu opera-

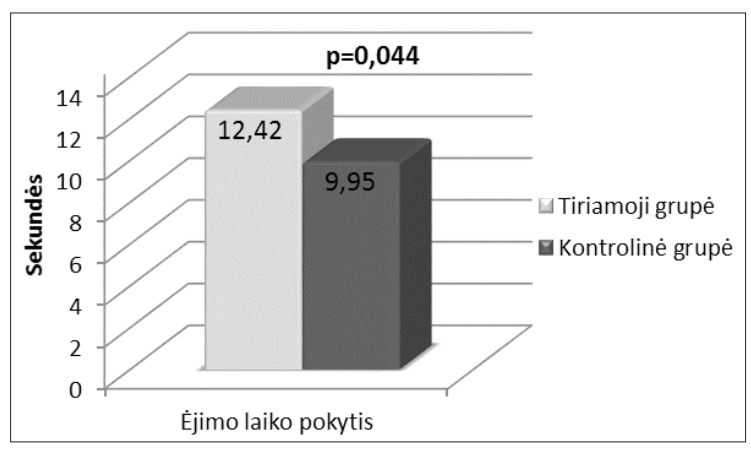

1 pav. Tiriamosios ir kontrolinės grupių tiriamųjų èjimo laiko pokyčių palyginimas ciniu pjūviu. Tyrime dalyvavo 34 moterys ir 26 vyrai. Visi tyrimo dalyviai atsitiktinai suskirtyti ị kontrolinę ir tiriamąją grupes. Neįtraukimo ị tyrimą kriterijai: minimalus protinès veiklos testo rezultatas mažesnis nei 20 balų, anksčiau keistas klubo ar kelio sąnarys, kardiovaskulinè patologija (širdies ritmo sutrikimai), asmuo atsisako dalyvauti tyrime. Tiriamają grupę sudare 29 pacientai, kuriems buvo taikyta ankstyva kineziterapijos metodika, kontrolinę grupę - 31 pacientas, kuriems buvo taikyta ịprastinè kineziterapijos metodika. Procedūros vykdytos du kartus per dieną, po $30 \mathrm{~min}$.

Visi testavimai tyrime atliekami tris dienas. Pradinis tiriamosios ir kontrolinès grupès raumenų jègos testavimas atliktas I dieną po operacijos, prieš I kineziterapijos procedūrą. Vertinta: izometrinè kojų atitraukejjų, pritraukejų ir šlaunies keturgalvio raumenu jèga rankiniu Lafayette dinamometru. Raumens jèga, matuojant Lafayette dinamometru išreiškiama niutonais. Matuota didžiausia jègos verte niutonais per 3 sekundžių trukmès raumenų susitraukimą. Matavimas pradètas po pirmojo garsinio signalo, baigtas po 3 sekundžių vienam po kito nuskambejjus trims garsiniams signalams.

Pradinis tiriamosios grupès $10 \mathrm{~m}$ èjimo (pulsas/laikas) testavimas atliktas I dieną po operacijos, II kineziterapijos procedūros metu. Kontrolinès grupès $10 \mathrm{~m}$ ejimo pradinis testavimas (pulsas/ laikas) atliktas II dieną po operacijos, III kineziterapijos procedūros metu. Galutinis kontrolinès ir tiriamosios grupès testavimas buvo atliktas III dieną po operacijos, V kineziterapijos procedūros metu.

\section{Tyrimo rezultatai}

Tiriamųjų kontingento charakteristika: pagal lytị, amžių ir pagal tai, kuri pacientų koja buvo operuota, tiriamoji ir kontroliné grupès buvo homogeniškos.

Pirminio testavimo metu tiriamosios ir kontrolinès grupių pacientų ejjimo laiko vidurkiai buvo labai panašūs ir statistiškai

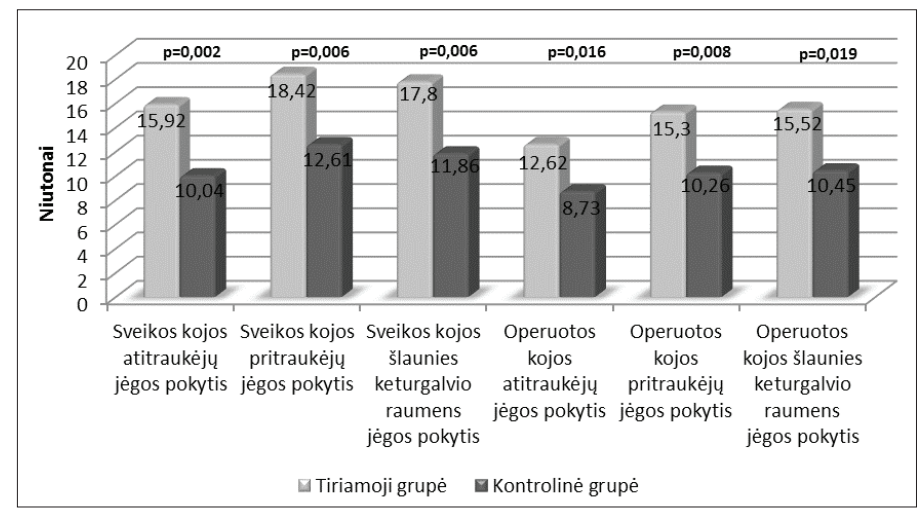

2 pav. Tiriamosios ir kontrolinès grupių tiriamujų sveikos ir operuotos kojos atitraukèjų, pritraukejjų ir šlaunies keturgalvio raumens jėgos pokyčių palyginimas 
reikšmingai nesiskyrė $(p>0,05)$. Po ankstyvos kineziterapijos tiriamosios grupès pacientų èjimo laikas (vid. $=18,91$ ) buvo statistiškai reikšmingai mažesnis nei kontrolinès grupès pacientų ejjimo laikas (vid. $=21,53$ ) po ịprastinès kineziterapijos $(\mathrm{p}<0,05)$. Palyginti tiriamosios ir kontrolinès grupių pacientų ejjimo laiko pokyčiai (1 pav.). Rezultatai parode, kad tiriamosios ir kontrolinès grupių pacientų èjimo laiko pokyčiai statistiškai reikšmingai skyrèsi $(p<0,05)$, t.y tiriamosios grupès pacientu ėjimo laikas sutrumpejo labiau nei kontrolinès grupès pacientų.

Analizuojant tiriamosios ir kontrolinès grupių pacientų fizini pajègumą palyginti pulso prieš testą, po testo, po 1 min, po $3 \mathrm{~min}$ ir po $5 \mathrm{~min}$ pokyčiai. Statistiškai reikšmingų skirtumų tarp tiriamosios ir kontrolinès grupių pacientų pulso pokyčių įvairiais testo etapais nenustatyta $(p>0,05)$, t.y. abiejų grupių tiriamujų pulsas visais matavimo etapais sumažèjo panašiai.

Pirminio testavimo metu abiejų grupių raumenų jègos buvo panašaus lygio ir statistiškai reikšmingai nesiskyre ( $>0,05)$. Po ankstyvos kineziterapijos tiriamosios grupès pacientų ir sveikos, ir operuotos kojos atitraukejjų, pritraukèjų ir šlaunies keturgalvio raumens jègos buvo statistiškai reikšmingai didesnès nei kontrolinès grupès pacientų sveikos ir operuotos kojų raumenų jègos po ịprastinès kineziterapijos $(p<0,05)$. Abiejose grupèse tiek pirminio, tiek ir galutinio testavimo metu mažiausia buvo operuotos kojos atitraukejų jèga. Abiejose grupèse didžiausios buvo sveikos kojos pritraukèjų ir šlaunies keturgalvio raumens jègos.

İvertinti tiriamosios ir kontrolinės grupių pacientų sveikos ir operuotos kojos atitraukejų, pritraukejjų ir šlaunies keturgalvio raumens jègos pokyčiai. Rezultatai parodè, kad statistiškai reikšmingai skyrèsi tiriamosios ir kontrolinès grupių pacientų sveikos ir operuotos kojos atitraukèjų, pritraukejjų ir šlaunies keturgalvio raumens jègos pokyčiai $(p<0,001)$ (2 pav.). Tiriamosios grupés pacientu raumenu jëga padidèjo reikšmingai daugiau nei kontrolinès grupès pacientų raumenų jëga.

\section{Diskusija}

Gauti tyrimo rezultatai sutampa su literatūros apžvalgos duomenimis, kad ankstyva kineziterapija labiau didina mobilumą nei ịprasta kineziterapija. Tiriamosios grupès pacientai statistiškai reikšmingai greičiau $(p<0,05)$ įveikè 10 metrų atstumą, nei kontrolinès grupès pacientai. Gauti rezultatai sutampa su A. Pogorzała ir kt. [12] atliktu tyrimu, kurio tikslas buvo išanalizuoti prieš ir po klubo sąnario endoprotezavimo operacijos eisenos greiti, taikant 10 $\mathrm{m}$ ejjimo testą. Rezultatai parodè, kad po taikyto gydymo statistiškai reikšmingai padidèjo èjimo greitis.

Ankstyva kineziterapija labiau didina raumenų jègą nei iprasta kineziterapija. Gautas statistiškai reikšmingi skirtumas $(p<0,05)$ tarp raumenų jègos pokyčių tiriamojoje ir kontrolinèje grupèse. Galutinio testavimo metu tiriamosios grupès pacientų raumenų jẻga buvo statistiškai reikšmingai didesnè nei kontrolinès grupès pacientų $(\mathrm{p}<0,05)$. Nustatyta, kad tiek tiriamojoje, tiek kontrolinejje grupeje, tiek pradinio, tiek ir galutinio testavimo metu mažiausia buvo operuotos kojos atitraukejjų jèga. Kaip teigia C. Martin [13] ir S. Petis su bendraautoriais [14], atliekant operaciją per priekinį - šoninị pjūvị, operacijos metu pažeidžiamas vidurinis sèdmens raumuo, būtent dèl to po operacijos susilpnèja šlaunies atitraukimas.

\section{Išvada}

1. Nustatyta, kad ankstyva kineziterapija labiau didina mobilumą, raumenų jègą nei iprasta kineziterapija. Gauti statistiškai reikšmingi skirtumai $(p<0,05)$ tarp mobilumo, raumenų jègos pokyčių tiriamojoje ir kontrolinèje grupèse.

\section{Literatūra}

1. Mikkelsen L, Mechlenburg I, Søballe K, Jørgensen L, Mikkelsen S, Bandholm T, Petersen A. Effect of early supervised progressive resistance training compared to unsupervised home-based exercise after fast-track total hip replacement applied to patients with preoperative functional limitations. A single-blinded randomised controlled trial. Osteoarthritis Cartilage 2014;22(12):2051-8.

http://dx.doi.org/10.1016/j.joca.2014.09.025

2. Zeni J, Pozzi F, Abujaber S, Miller L. Relationship between physical impairments and movement patterns during gait in patients with end-stage hip osteoarthritis. J Orthop Res 2015;33(3):382-9.

http://dx.doi.org/10.1002/jor.22772

3. Pogorzała A, Stryła W, Nowakowski A. Functional activity in patients after total hip replacement. Polish Orthopedics and Traumatology 2012;8;77:121-5.

4. Lietuvos sveikatos statistika. Vilnius, 2014.

5. Aprile I, Rizzo R, Romanini E. Group rehabilitation versus individual rehabilitation folloeing knee and hip replacement: a pilot study with randomized, single - blind, cross - over design. Europian Journal of Physical and Rehabilitation Medicine 2011;47(4):551-559.

6. Stryla W, Pogorzala A, Rogal P. Algorithm of physical therapy exercises following total hip arthroplasty. Polish Orthopedics and Traumatology 2013;78:33-39.

7. Berger R, Sanders S, Thill E, Sporer S, Della Valle C. Newer anesthesia and rehabilitation protocols enable outpatient hip replacement in selected patients. Clinical Orthopaedics and Related Research 2009;467(6):1424-30. http://dx.doi.org/10.1007/s11999-009-0741-x

8. Husted H, Hansen HC, Holm G, Bach-Dal C, Rud K, Andersen 
KL, Kehlet H. Length of stay in total hip and knee arthroplasty in Danmark I: volume, morbidity, mortality and resource utilization. A national survey in orthopaedic departments in Denmark. Ugeskrift for Laeger 2006;29;168(22):2139-43.

9. Husted H, Lunn T H, Troelsen A, Gaarn-Larsen L, Kristensen B B, Kehlet H. Why still in hospital after fast-track hip and knee arthroplasty? Acta Orthopaedica 2011;82(6):679-84. http://dx.doi.org/10.3109/17453674.2011.636682

10. Winther S, Foss O, Wik T,Davis S,Engdal M, Jessen V, Husby O. 1-year follow-up of 920 hip and knee arthroplasty patients after implementing fast-track. Acta Orthopedica 2015;86(1):78-85.

http://dx.doi.org/10.3109/17453674.2014.957089

11. Beyer N, Suetta C. Older patients should be offered strength training early post surgery. Ugeskrift for Laeger 2013;175(41):2421-4.

12. Pogorzała A, Stryła W, Nowakowski A. The effect of hip arthroplasty on the speed of walking. Polish Orthopedics and Traumatology 2013;15;78:201-5.

13. 13. Martin C, Pugely A, Gao Y. A comparison of hospital length of stay and short-term morbidity between the anterior and the posterior approaches to total hip arthroplasty. The Journal of Arthroplasty 2013;28:849-54.

http://dx.doi.org/10.1016/j.arth.2012.10.029

14. Petis S, James L, Brent L. Lanting M. Surgical approach in primary total hip arthroplasty: anatomy, technique and clinical outcomes. Canadian Journal of Surgery 2015;58(2):128-139. http://dx.doi.org/10.1503/cjs.007214

\section{FAST - TRACK EFFECT ON MOBILITY AFTER HIP ARTHROPLASTY}

\section{Lizdenienė, S. Lenickienè}

Key words: fast - track, mobility, pain, anxiety, hip replecment. Summary

Application of new fast-track methods following endoprosthetic hip surgery results in faster recovery for the patients as well as earlier rehabilitation of working capacity. Consequently, the patients may be discharged the third or fourth day following their surgery. The purpose of the research was to determine the influence of fast-track methods on mobility, pain and anxiety during acute period following endoprosthetic hip surgery. The research was being conducted at the Centre of Orthopaedics and Traumatology of Vilnius University Hospital Santariskiu clinics from April 2015 to March 2016. 60 patients who had undergone endoprosthetic hip surgery by anterior-lateral incision, including 34 female and 26 male patients, took part in the research. Their mobility was assessed by performing a 10-meter walk test and, in order to determine physical fitness, their pulse was measured before the test, right after the test, 1 minute, 3 minutes and 5 minutes after the test and isometric strength of leg abductors, adductors and knee extensors was tested using a manual Lafayette dynamometer. The research revealed that fast-track does more to improve mobility and muscle strength than common kinesiotherapy. Statistically significant differences $(p<0.005)$ in mobility and muscle strength changes were obtained in the experimental and control groups.

Correspondence to: vitazemaitis@gmail.com

Gauta 2016-06-09 